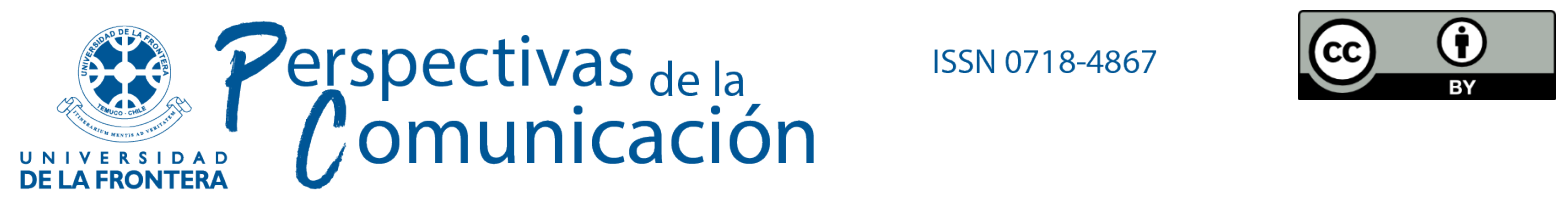

Artículo

\title{
CIUDAD/COMUNICACIÓN/CULTURA HACIA UNA PERSPECTIVA TRANSDISCIPLINARIA
}

https://doi.org/oO.ooo/COO-202O-O1

\author{
Dra. María Eugenia Boito \\ Universidad Nacional de Córdoba, Córdoba, Argentina. \\ meboito@yahoo.com.ar \\ ORCID iD: https://orcid.org/oooo-0o02-5833-8974
}

Recibido el 6 de diciembre de 2018

Aceptado el 14 de junio de 2019

\section{Resumen}

Este artículo se orienta hacia la construcción de una perspectiva transdisciplinaria para reflexionar sobre el campo de debates que convergen en su título: Ciudad/Comunicación/Cultura. En este sentido, las reflexiones parten de retomar algunas producciones que van en esta orientación, previo reconocimiento de la convergencia histórica que se viene realizando en la región de América Latina en particular entre los estudios urbanos, por un lado, y los estudios en comunicación por el otro. Luego proponemos la referencia a dos tendencias que van produciendo las ciudades de manera creciente: la mercantilización y la mediatización de la experiencia de los actores.

Intentaremos, recuperando distintos autores del campo de la comunicación, dar cuenta de los rasgos y las dinámicas que prevalecen en la producción de escenarios urbanos contemporáneos, indicando el carácter productor de la ciudad. Recuperamos, así, las íntimas relaciones entre ciudad capitalista/turistificada, comunicación mercantil/publicitaria, y la construcción de lazos sociales subsumidos por la lógica del capital.

$\mathrm{Al}$ avanzar en el artículo, reflexionamos fenomenológicamente sobre dimensiones de la vida urbana actual, en Córdoba y otras ciudades del país: sujetos con dispositivos pegados al 
cuerpo, en barrios cerrados, con trayectorias fijas de movilidad, con niños asesinados para cuidar las mercancías; conformando nuestra sensibilidad y el sensorium colectivo.

Para nosotros la ciudad no sólo se considera como escenario o continente, como marco o encuadre; sino que en la actualidad la ciudad tiene un rol activo en la producción de formas de estar juntos/estar separados. Así también, de dar luchas contra el capitalismo.

Palabras clave: ciudad, comunicación, cultura, transdiciplinariedad. 


\title{
CITY/COMMUNICATION/CULTURE TOWARDS A TRANSDISCIPLINARY PERSPECTIVE
}

\begin{abstract}
This article is oriented to build a transdisciplinary perspective to study the area of knowledge and debates that converge in the title of this text: City/Communication/Culture. Therefore, our proposal begins by recovering some former productions which aim towards that goal, recognizing the historical convergence that has occurred in Latin America between urban and communication studies. After that we refer to two tendencies which cities are gradually producing: commodification and medialization of actor's experiences.

By recovering different authors, we will try to present the features and dynamics that prevail in the production of urban sceneries, indicating the productive character of cities. We refloat the intimate relations between capitalist/touristified cities, market/publicity oriented communication and the construction of social bonds subsumed by capital's logic.

After such a presentation, we will reflect fenomenologically about some current dimensions in urban life, particularly in Cordoba and other cities of Argentina: subjects with devices attached to their bodies, in closed neighborhoods, with fixated trajectories, with children being killed to guard commodities, and forming at the same time our sensibilities and collective sensorium.

From our point of view, the city is not only scenery or a continent, a picture or a frame. Instead, the city has an active role in the production of ways of being together/being apart. But also, in the ways of fighting capitalism.
\end{abstract}

Keywords: city, communication, culture, transdisciplinarity. 


\section{Introducción}

Desde el título este trabajo se orienta hacia la construcción de una perspectiva transdisciplinaria, para dar cuenta de los rasgos y las dinámicas que prevalecen en la producción de escenarios urbanos contemporáneos; concretamente partiendo de lo que Jesús Martín-Barbero piensa en términos de comunicación: "los modos populares de relacionarse y las maneras que tiene la gente de estar/sentirse juntos" (2015: 6), pero desde nuestra perspectiva, agregando y tensionando esas formas de estar juntos con las formas estar separados que también constituyen y redefinen a las primeras dialécticamente.

Por ello, las reflexiones parten de algunas producciones que van en esta orientación, previo reconocimiento de la convergencia histórica que se viene realizando en la región de América Latina en particular entre los estudios urbanos por un lado y los estudios en comunicación por el otro; luego proponemos la referencia a dos tendencias que van produciendo las ciudades de manera creciente: la mercantilización y la mediatización de la experiencia de los actores. Nos detenemos aquí en vistas a exponer la trama entre Ciudad/Comunicación /Cultura que se hace visible a partir de la identificación analítica y la operatoria de las tendencias antes referidas. Finalmente, y como cierre remitimos a un hecho noticioso que condensa las consideraciones expuestas en el trabajo, en un contexto atravesado por la cruenta mercantilización de la vida y la fragmentación recurrente de las posibilidades de encuentro entre sujetos y colectivos sociales.

\section{Ciudad /Comunicación/Cultura. Una lectura sobre el estado de la cuestión}

Paula Vera estuvo a cargo de la edición del número dedicado a los estudios de ciudad y estudios en comunicación, titulado "Ciudad y comunicación, imaginarios, subjetividades y materializaciones” publicado en la Revista InMediaciones de la comunicación, a fines de 2017. Partimos de su intervención nominada "Ciudad y comunicación. La actualidad de un campo transdisciplinar". Citamos:

En los últimos años se evidencia un nuevo impulso en el campo de estudios sobre ciudad-comunicación / comunicación-ciudad, algo que se vio influenciado por los nuevos interrogantes que proponen las problemáticas vinculadas a la renovación tecnológica digital. A su vez, el impacto de la lógica neoliberal en la ciudad contemporánea abre nuevas problemáticas y profundiza otras existentes. La segregación socio-espacial, la mercantilización creciente, los nuevos mecanismos, en muchos casos sutiles, de privatización de espacios públicos, la fetichización, patrimonialización y turistificación de sitios, objetos, emblemas y símbolos urbanos que impactan en el lazo social y sentido de pertenencia a la ciudad, la creciente violencia urbana, la complejización de las organizaciones delictivas, los procesos de 
gentrificación y las disputas en torno a los espacios urbanos abren todo un nuevo espectro en donde, para comprender los modos de vida actuales, es imprescindible entrelazar estudios complejos que aborden los planos materiales, subjetivos, imaginarios y de las prácticas sociales. (Vera, 2017: 27)

En su abordaje de las producciones en lo que denomina el campo comunicación/ciudad- en una lectura que historiza los últimos 70 años en las producciones del continente- la autora señala la existencia de un doble movimiento, a partir ciertas acumulaciones de producciones teóricas e investigaciones en el campo de los estudios urbanos por un lado y más adelante, por parte de los estudios desde la comunicación, a partir de los procesos de desarrollo más autónomos desde esta instancia. Doble movimiento que en la actualidad se orienta hacia la configuración de un abordaje transdisciplinar en el cual las transformaciones urbanas requieren ser pensadas desde su incidencia en procesos y prácticas de comunicación a escala micro-meso y macro social; y a la vez la creciente centralidad de las tecnologías de comunicación que convocan a ser consideradas al momento de indagar su incidencia en la vida urbana.

En el recorrido que concreta la investigadora, recupera la figura de Robert Park quien elabora un tipo de propuesta teórica que anticipa la convergencia que hoy va caracterizando la perspectiva transdisciplinaria que se va constituyendo en el presente.

Según Park (1999), citado en Vera (2017), los principales factores de la organización ecológica de la ciudad serían los medios de transporte y de comunicación, los periódicos, la publicidad, los tranvías y teléfonos. Esta perspectiva, entonces, pone especial atención a ciertos elementos propios de la comunicación social que aún no se constituía como disciplina pero que, a partir de la década de 1940 comenzaría a definir su objeto de estudio. (Vera, 2017: 23)

Desde nuestra lectura Robert Park primero y Ludovico Silva (1977) más adelante, enfatizan una dimensión fundamental al momento de configurar un lugar de interpretación sobre los procesos de construcción del sentido de la vida social, desde una perspectiva que señala la pertinencia de identificar los cambios en los medios de transporte (de sujetos, mercancías e ideas) y el lugar de la circulación en el marco de los procesos de producción/reproducción social y la inscripción de los desarrollos de las tecnologías en esta instancia en el marco de una perspectiva materialista. Sobre esta idea volveremos más adelante. 
Por otra parte, un artículo de Daniel Badenes titulado "Comunicación y ciudad: líneas de investigación y encuentros con la historia cultural urbana” (2007), se propone relevar los estudios que han tenido por objeto pensar la ciudad desde la comunicación (las cursivas nos pertenecen). Esta intervención nos permite avanzar en la presentación de nuestro punto de vista. Algunas preposiciones (desde, en) así como ciertas conjunciones (y), han causado dificultades en los intentos por expresar los vínculos entre comunicación, cultura, ciudad. Por nuestra parte, retomamos el proyecto de Héctor Schmucler (1997) que recurre a la barra para pensar la trama comunicación/cultura, y conformamos una tríada en la cual el primer lugar lo ocupa la noción de ciudad. Así lo que vamos a empezar a desarrollar es la trama Ciudad/Comunicación/Cultura.

Retomemos el artículo de Badenes, específicamente su consideración sobre el estado de los estudios e investigaciones en la región desde mediados de los '80:

\begin{abstract}
Tras su ruptura con el "mediacentrismo", la comunicación se ha dado múltiples objetos de estudio. Este ensayo se dedica a uno de ellos: la ciudad. Las investigaciones que problematizan la relación comunicación / cultura / ciudad se consolidaron a principios de los ' 90 , con la organización de espacios académicos específicos, la formulación de proyectos de investigación y la publicación de "hitos" editoriales (...) En nuestra región data de los años ochenta, como parte de ese corrimiento del objeto de estudio que se sintetizó en el pasaje de los medios a las mediaciones, según la consagrada expresión utilizada por Martín Barbero. Valga mencionar ese hito -como podrían citarse obras de otros investigadores, como el Proyecto de comunicación / cultura de Schmucler o la Propuesta de una genealogía de la comunicación de Mattelart- para dar cuenta del bosque de desplazamientos teóricos cuyas significaciones, motivaciones y alcances ya han sido trabajados en otros textos. (Badenes, 2007: 1)
\end{abstract}

Badenes da cuenta de la emergencia de un privilegiado objeto para los comunicólogos a partir del abandono de los medios; fundamentalmente a partir de la pérdida del peso relativo de las lecturas semióticas/critico ideológicas sobre los mensajes masivos y las miradas referidas a la propiedad de los medios desde la economía política, para dirigirse hacia la interrogación sobre la recepción y los usos de los productos. Más precisamente: abandono de los medios "tradicionales" para pensar los procesos, las prácticas y nuevos medios emergentes (FM en una primera instancia y posteriormente la TV por cable, por citar solo algunos ejemplos) a partir de dos cambios: uno contextual, a saber, la vuelta de la democracia en el continente como hecho político; y el otro, propio del campo de reflexión en configuración, donde el acceso a la publicación de obras de Michel de Certeau en español desde 1996 en adelante, quien subrayó el desplazamiento de las investigaciones sobre los 
usos y las maneras de marcar socialmente tanto productos culturales como territorios -y aquí, la ciudad como objeto de estudio de tales expresiones, itinerarios, inscripciones ${ }^{1}$.

Por nuestra parte consideramos que en las referencias expuestas hasta aquí se olvida una publicación fundamental, en vistas a sostener nuestro punto de vista que remite al vínculo Ciudad/Comunicación/Cultura, atravesado por tendencias crecientes de mercantilización y mediatización de la experiencia. Nos referimos a "Las culturas populares en el capitalismo", texto de Néstor García-Canclini del año 1982 en el cual analiza como fenómeno los cambios en las fiestas populares y en las artesanías en zonas rurales de México, en función del tramado de recorridos turísticos en los que se van a ir inscribiendo las culturas populares. Estas prácticas:

sintetizan los principales conflictos de su incorporación al capitalismo. En la producción, circulación y el consumo de las artesanías, en las transformaciones de las fiestas, podemos examinar la función económica de los hechos culturales: ser instrumentos para la reproducción social; la función política: luchar por la hegemonía; las funciones psicosociales: construir el consenso y la identidad, neutralizar o elaborar simbólicamente las contradicciones (García-Canclini, 1982: 57)

Es decir, da cuenta de un desplazamiento en la indagación hacia zonas rurales que anticipa lo que está ocurriendo hoy en las ciudades latinoamericanas, a partir del avance del turismo como una de las formas expresivas de la economía espectacular-mercantil -sensu Guy Debord (2006)- que produce "paquetes de experiencia" mediatizados/mercantilizados. En el próximo apartado desarrollaremos nuestra interpretación sobre las tendencias referidas.

1 No podemos dejar de remitir a las expresiones de Rossana Reguillo (1997) sobre este tópico en el artículo titulado Ciudad y comunicación. Densidades, ejes y niveles: "Estudiar la ciudad desde la comunicación, las formas de vida, las apropiaciones territoriales de signos diversos, las representaciones y la significación, los "consumos" culturales, la presencia de los medios, la irrupción de la ciudadanía, no es tarea sencilla, se impone una reflexión sobre cómo han sido pensados estos objetos y cómo han sido construidos; trabajar con rigor y sistematicidad -tenazmente- atreverse a salir de los compartimientos estancos, de la univocidad de los marcos conceptuales". Disponible en: http://dialogosfelafacs.net/wp-content/uploads/2015/74/74-revistadialogos-ciudad-y-comunicacion.pdf 


\title{
2. Ciudad/Comunicación/Cultura. Las tendencias de mercantilización y mediatización de la experiencia
}

Hasta aquí hemos señalado que la trama Ciudad/Comunicación/Cultura se inicia con la noción de ciudad. Empezamos a aproximarnos desde definiciones negativas, para finalmente concretar nuestra propuesta de lectura y exponer la hipótesis de trabajo en la que la noción de ciudad se trama con las tendencias de mediatización y mercantilización creciente de la vida social. Para nosotros la ciudad no sólo se considera como escenario o continente, como marco o encuadre; sino que en la actualidad la ciudad tiene un rol activo en la producción de formas de estar juntos /estar separados. García-Canclini (1982) indicaba las transformaciones de las culturas populares (rurales, campesinas) a medida del avance del capitalismo sobre estos territorios y poblaciones. Por nuestra parte, lo que vamos a subrayar es el íntimo lazo entre ciudad y desarrollo del capitalismo.

De manera recurrente David Harvey ha señalado esta idea: "La estructura de la ciudad es el producto de la dinámica capitalista". En el artículo "El Derecho a la Ciudad”, expresa:

\begin{abstract}
Desde sus inicios, las ciudades han surgido mediante concentraciones geográficas y sociales de un producto excedente. La urbanización siempre ha sido, por lo tanto, un fenómeno de clase, ya que los excedentes son extraídos de algún sitio y de alguien, mientras que el control sobre su utilización habitualmente radica en pocas manos. Esta situación general persiste bajo el capitalismo, por supuesto; pero dado que la urbanización depende de la movilización del producto excedente, surge una conexión íntima entre el desarrollo del capitalismo y la urbanización. Los capitalistas tienen que producir un producto excedente a fin de producir plusvalor; éste a su vez debe reinvertirse para generar más plusvalor. El resultado de la reinversión continuada es la expansión de la producción de excedente a un tipo de interés compuesto, y de ahí proceden las curvas logísticas (dinero, producción y población) vinculadas a la historia de la acumulación de capital, que es replicada por la senda de crecimiento de la urbanización en el capitalismo. (Harvey, 2008)²
\end{abstract}

\footnotetext{
2 Es conveniente recordar que la acumulación originaria fue de tierra. Procesos de expropiación del suelo de la población rural, de la mano de legislación contra los "liberados" que no aceptaban las nuevas reglas de juego, a partir de fines del siglo xv. Más adelante esas poblaciones se transformarán en fuerza de trabajo con el desarrollo del capitalismo industrial. Y van a devenir en superfluas o supernumerarias -no más ya "ejercito de reserva"- en nuestro tiempo denominado capitalismo de casino, (Kurtz, 2016); patriarcado productor de mercancías, (Scholz, 2013); economía espectacular-mercantil (Debord, 1995, 2006). El tiempo circular de la naturaleza fue roto y se ha creado el tiempo circular del capital, previa unificación del tiempo, construcción de su carácter como lineal y exacerbación de la velocidad de la circulación (de cuerpos, mercancías e ideas). Sobre las ideas de circulación y velocidad volveremos más adelante.
} 
Harvey (2008) refiere al vínculo existente entre urbanización y capitalismo, remitiendo a la remodelación de la ciudad de París por Haussmann y al crecimiento de las ciudades contemporáneas, como manifestación y respuesta a la crisis sistémica de acumulación de capital. Es sabido que el geógrafo inglés retoma de Henri Lefebvre la siguiente idea: la ciudad es el campo decisivo a partir del cual se debe repensar y reorganizar la lucha contra el capitalismo y por su parte exige la democratización del poder para modificar la experiencia urbana.

Pero si de manera cada vez más intensa "la producción de ciudad" se concreta como precarización de las posibilidades de vida de sus habitantes hasta el punto de la destrucción de las mismas - posición enfatizada desde tiempo antes por los situacionistas, donde las transformaciones urbanas hacían imposible la participación, la comunicación y la realización de uno mismo- creemos necesario señalar que para nosotros y a partir de las experiencias urbanas que hemos estudiado en la ciudad de Córdoba durante 15 años, nuestra ciudad va dejando de ser un campo de lucha y su misma forma es cada vez más productiva y posibilitadora del despliegue de las tendencias antes referidas.

Esto marca una fuerte contradicción para las luchas emancipatorias, y veremos en próximos apartados que las cuestiones sociourbanas planteadas por algunos colectivos cordobeses desde barrios pericentrales (cuyo eje se sintetiza en alguna de las consignas, por ejemplo "Paren de demoler" por parte de la Multisectorial Defendamos Alberdi ante el avance de los autodenominados "desarrollistas urbanos") configuran frecuentemente reacciones defensivas, como resultante de un proceso histórico de transformación sustantiva de los horizontes de posibilidades y de los marcos de expectativas de las acciones de protesta de estos colectivos y de otros precedentes, que hoy ya no existen o se encuentran fragmentados y debilitados.

En síntesis, lo que queremos remarcar es lo siguiente: la necesidad de repensar y reorganizar la lucha contra el capitalismo encuentra en las ciudades contemporáneas no un espacio o campo "neutro" sino un terreno marcado, dispuesto, organizado, construido donde se expresan y materializan las relaciones capitalistas -“entre cosas"- de acuerdo a los pares "carne y piedra" - como sostuvo Richard Sennett (1997)- y "técnica y sensorium” -tal como lo expresó Walter Benjamin (1999a)-, como objetivaciones en la ciudad del predominio de relaciones entre cosas que moldean la experiencia urbana de sus habitantes.

En la misma dirección expuesta agrega Harvey más adelante:

Perspectivas de la Comunicación - Vol. 13 - No 2 - 2020 - pp. 43-72

Universidad de la Frontera - Chile 
Como en todas las fases precedentes, esta última radical expansión del proceso urbano ha traído aparejadas increíbles transformaciones de los estilos de vida. La calidad de la vida urbana se ha convertido en una mercancía, como la ciudad misma, en un mundo en el que el consumismo, el turismo, las industrias culturales y las basadas en el conocimiento se han convertido en aspectos esenciales de la economía política urbana (Harvey, 2008)

El geógrafo inglés sostiene que la ciudad misma se ha convertido en mercancía; aquí la ciudad puede ser pensada como: a- con relación a otras ciudades y a la lógica del turismo a escala global como Marca/Ciudad (y la consecuente transformación de los espacios y tiempos de habitar/trabajar/circular de los sujetos en función del plan de turistificación y/o patrimonialización actuante en la misma) (Boito, M. E., Espoz, M. B. y Torres, P. 2018); bcon relación a las "piedras" con las que está conformada: aquí, la ciudad como mercancía es esa instancia productora de relaciones entre cosas que subsume las relaciones entre sujetos y clases (en nuestra provincia, el vínculo campo-ciudad del modelo productivo basado en la siembra/exportación de soja se visibiliza, por ejemplo, en las megaconstrucciones de complejos habitacionales vacíos, deshabitados que funcionan como ca(s/j)a fuerte de ladrillos para sus inversores, no para las demandas habitacionales de los sujetos que la habitan); y, c- con relación a la "carne"/sensibilidades de sus habitantes. Aquí la ciudad es imagen, en el sentido de vivencia espectacular que mantienen los sujetos con ella, ya sea por las modificaciones urbanas que crean entornos de clase y círculos de encierro clasista donde "los mismos interactúan entre los mismos", en función de la composición homogénea de clase que particulariza a estas urbanizaciones-, ya sea por las mediaciones tecnológicas implicadas y cada vez más "naturalizadas” en las prácticas de la reproducción cotidiana de la vida en la ciudad.

Ciudad/Comunicación/Cultura. Estamos indicando el carácter productor de la ciudad; carácter productor de relaciones, atravesadas por tendencias crecientes de mercantilización y mediatización de la experiencia que redefinen las formas de estar juntos y estar separados. Y la siguiente es nuestra hipótesis de trabajo, en la que concretamos un primer enlace: La trama Comunicación/Cultura; es decir las relaciones sociales por definición plurales y heterogéneas en cuanto a la construcción de significados sobre la vida con otros y con el entorno, sobre la propia experiencia, expresada en los más variados lenguajes, objetivada en distintos soportes, configurada en múltiples géneros, viene siendo subsumida por una forma dominante - la comunicación devenida en discurso publicitario- y expone la marca del mercado en la estructura y en la estructuración de las relaciones sociales. No se trata 
de un problema de discurso - el discurso publicitario- sino de la identificación de una (la) forma dominante del lazo social: del sujeto consigo mismo, con los otros, con el entorno. La ciudad capitalista -el adjetivo solo remarca las marcas propias de la ciudad contemporánea- es productora de este tipo de lazo que en su recurrencia modela y moldea un tipo de experiencia, donde los rasgos y la dinámica de la lógica de la equivalencia se van instaurando como una especie de "fe perceptual"; punto ciego que organiza el ser/estar/parecer en la ciudad. Parafraseando a Ludovico Silva y ubicándonos un paso más allá: no se trata ya de la conocida afirmación "Homo Homini Mercator"; o sea, el hombre es mercancía para otro hombre ${ }^{3}$, sino que de manera creciente son las relaciones entre cosas entre mercancías- y en la ciudad como mercancía lo que conforma la vida urbana contemporánea. La Marca/Ciudad es quizás la manifestación más prístina del discurso publicitario en como lazo tanto para sus habitantes y para los turistas/consumidores; pero a la vez es pertinente hacer foco en la alocada circulación de "mini” marcas que definen formas distintas y desiguales de percibir/estar en la ciudad. Las publicidades de las llamadas "nuevas ciudades" -si nos centramos a mirar la disposición de estas "piedras" en las urbanizaciones de encierro entre iguales a las que hemos referido-; expresan un particular vínculo entre el habitar/trabajar/circular/consumir/ de ciertas clases ${ }^{4}$. De este modo si como afirma Harvey "La calidad de la vida urbana se ha convertido en una mercancía" (2008), desde nuestra perspectiva se hace necesario retomar las intervenciones de los pensadores situacionistas, al momento de concretar un primer acercamiento a la idea de mercantilización.

En "De la miseria en el medio estudiantil", los diversos autores que escribieron en conjunto este texto a fines de los años 6o, queda definida con claridad esta idea:

3¿De qué forma está constituida la expresión ideológica de la producción de plusvalía material en el capitalismo actual? ¿Cómo debería llamarse? ¿De qué manera el capitalismo procede a justificarse en las mentes de los hombres? ¿A través de argumentos racionales? ¿O a través de presiones ejercidas sobre capas mentales inconscientes, las cuales son tierra fértil para hacer que los hombres crean que justifican el sistema y no que el sistema se justifique en sus mentes? ¿De qué forma los hombres hacen suya la creencia ideológica de que el mundo es un mercado de mercancías? (Silva, 1977, 193- 194). Por ejemplo, ver: Boito, M. E. (2013) y Boito, M. E. (2014).

4 Se pueden consultar las siguientes páginas web: MANANTIALES 360. GRUPO EDISUR: Pagina web. Córdoba, Argentina. Disponible en: http://www.grupoedisur.com.ar/web/es/manantiales-36o/ [Consulta: 15/12/2017]

CIUDAD GAMA. Página web, Córdoba, Argentina. Disponible en: http://gama-sa.com/ciudad-gama/. [Consulta: 6/o1/2018]

Perspectivas de la Comunicación - Vol. 13 - No 2 - 2020 - pp. 43-72

Universidad de la Frontera - Chile 
La lógica de la mercancía es la racionalidad primera y última de las sociedades actuales, la base de la autorregulación totalitaria de estas sociedades, comparables a rompecabezas cuyas piezas, tan desemejantes en apariencia, son en realidad equivalentes. (...) En el mundo de la producción mercantil, la praxis no se persigue en función de un fin determinado de forma autónoma, sino bajo las directrices de potencias exteriores. Y si las leyes económicas parecen convertirse en leyes naturales de un tipo particular, es porque su poder reposa únicamente sobre "la ausencia de conciencia de quienes toman parte de ello" (AA VV, 2018: 67) (Las cursivas nos pertenecen) 5

Debord (2006, 2000, 1995) en su época así como los teóricos actuales de la Teoría del Valor -A. Jappe, Claus-Peter Ortlieb y R. Kurtz (2009), entre otros- indican que es necesario considerar la ampliación del campo de acción de la relación entre la lógica de la mercancía y la equivalencia ${ }^{6}$, en vistas a construir reflexivamente una crítica detenida y precisa sobre la Teoría del Valor. Desde otro lugar, pero con la misma orientación, Sandro Mezzadra (2014) indica que el valor es un lenguaje cuya estructura semántica y su gramática generan un tipo de interpelación en la cual los heterogéneos lenguajes (heterogéneas formas de Comunicación/Cultura, como las fiestas y artesanías mexicanas investigadas por García Canclini (1982) a las que hemos referido) se van adecuando al lenguaje del valor y a la lógica de la equivalencia con la que está asociada.

\section{Ciudad/Comunicación/Cultura. Algunas expresiones de las tendencias de mercantilización y mediatización de la experiencia en la ciudad cordobesa}

Para seguir pensando esta tríada atravesada por la mercantilización y la mediatización, vamos a referir a algunos de los resultados de nuestras investigaciones en la ciudad de Córdoba. Desde hace más de una década estudiamos las transformaciones urbanas y el ordenamiento clasista de la ciudad, preguntándonos por los cambios en las formas de circulación y de hábitat, como resultantes de decisiones socio-económicas y socio-urbanas que han modificado los lugares de habitar, circular y trabajar, en función de

\footnotetext{
5 Este lenguaje del valor como punto ciego de la percepción, es producto y producción a la vez. Como resultante o producto, es siempre provisorio y contingente; como producción, supone la necesaria referencia a la historia cultural de la configuración burguesa de la percepción, que organiza la naturaleza sensible de la práctica; o sea, las fibras que forman los pensamientos/sentimientos de la experiencia que orientan las acciones de los sujetos.

6 Con respecto a este tema, A. Jappe ha realizado varias publicaciones. Desde el clásico texto de 1998 titulado Guy Debord (1998) hasta producciones más contemporáneas: El absurdo mercado de los hombres sin cualidades, en colaboración con Robert Kurz y Claus-Peter Ortlieb (2009). Mientras que la obra más importante de Kurtz es El colapso de la modernización. Del derrumbe del socialismo de cuartel a la crisis de la economía mundial. Texto de 1991 que en 2016 se traduce al español.
} 
reconfiguraciones en el par cuerpo-clase. Hemos profundizado en la relación estadomercado y sus intereses convergentes -intereses de clase- efectivizados en políticas concretas. En ese marco, construimos un diagnóstico de la ciudad de Córdoba en términos de embellecimiento estratégico, en referencia al proceso descripto por W. Benjamin con relación a los cambios en la ciudad de París diseñados por Haussmann, que enfatiza el contenido y la intencionalidad política de los cambios urbanos, dispuestos en función de evitar y controlar la emergencia del conflicto social y regular las interacciones sociales en un sentido clasista7 7 Hemos recorrido diversos abordajes: desde una mirada más centrada en la acción colectiva, en las que destacaba la lucha por el acceso al hábitat, hasta la violencia estatal “dulcificada" del Programa "Mi Casa, Mi Vida”, no sólo en relación a la modalidad de la política, sino también a la coagulación de la acción, a la paralización del conflicto. Luego, considerando "la ciudad" que había permitido/incluso celebrado/ la implementación de dicha operatoria expulsógena y alterofóbica, indagamos en las sensibilidades implicadas, sostenidas a través de discursos mediáticos, de las políticas estatales en relación al centro histórico y sus barrios aledaños. Reconocimos la construcción de un perfil urbano de ciudad turística, de ciudad espectáculo para ser admirada y consumida ${ }^{8}$.

Paralelamente, en ciertos barrios pericentrales hemos observado cómo la segregación toma la forma de gentrificación, es decir, desalojo -más o menos explícito o violento- de clases populares para la instalación de proyectos inmobiliarios destinados a la inversión, vivienda, recreación o consumo de turistas o sectores de ingresos medios y altos. Y aquí hemos vuelto a centrar la mirada en la acción colectiva, que de diversas maneras y con variados niveles de organización, resiste y se opone al proceso de expropiación capitalista y el modelo

7 Las casas del centro no estaban desiertas ni habían sido revendidas a espectadores de cine que nacieron en otros lugares, bajo otras vigas a la vista. La mercancía moderna no había llegado aún a enseñarnos todo lo que puede hacerse de una calle. Nadie estaba obligado, a causa de los urbanistas, a ir a dormir lejos. No se había visto aun oscurecerse el cielo y desaparecer el buen tiempo por culpa del gobierno, ni la bruma postiza de la contaminación cubrir permanentemente la circulación mecánica de las cosas en este valle de desolación. Los arboles no habían muerto ahogados, y el progreso de la alienación no había apagado las estrellas (Debord, 2000: 30-31).

8 Subproducto de la circulación de mercancías, la circulación humana considerada como un consumo, el turismo, se reduce fundamentalmente al ocio de ir a ver aquello que ha llegado a ser banal. La organización económica de la frecuentación de lugares diferentes es ya por sí misma la garantía de su equivalencia. La misma modernización que ha retirado del viaje el tiempo le ha retirado también la realidad del espacio (Debord, 1995, tesis 168). 
hegemónico de ciudad, en barrios donde emergen organizaciones que instalan una disputa por tener/mantener un lugar. En Alberdi, San Vicente, Güemes, San Martín y El Tropezón, la Multisectorial Defendamos Alberdi, la Red de Vecinos de San Vicente, el Movimiento Cultural Barrio San Martín, vecinos adultos y jóvenes que resisten los intentos de desalojo en Villa El Tropezón, artesanos de Güemes, entre otros, se constituyen como actores sociales en espacios de tensión urbana, donde luchan por permanecer y en los que anudan una historia común y una identidad que se inscribe en una matriz de vida barrial amenazada.

Sobre la cartografía de Córdoba es posible observar no sólo cómo se ha ido expulsando a los sectores populares hacia los márgenes, cómo se ha acrecentado la segregación residencial socioeconómica (Molinatti 2013), y también el creciente desarrollo de formas habitacionales “de encierro" y la distancia entre grupos sociales (Boito y Espoz, 2014). Así, la construcción de "entornos clasistas" refiere al ordenamiento físico y sensible que, de maneras diferentes pero convergentes, tiende a construir experiencias sociales "entre los mismos de clase": relocalizando forzosamente a las clases populares, transformando barrios pericentrales en función de intereses del mercado -productivo, turístico e inmobiliario-, promoviendo la vida para las clases altas en countries, barrios cerrados o complejos de torres de "alta gama". Éstos constituyen a su vez "regiones" urbanas, que concentran tipos de espacios y clases sociales, que se expanden para grupos socioeconómicos altos en la periferia noroeste y sur de Córdoba, principalmente hacia las sierras. Importantes núcleos de pobreza, en cambio, se organizan en las zonas Este, NE y SE. Como ya hemos dicho, pornográficamente se nominan ciudades, ciudades-barrio para el caso de los pobres (Ciudad de los Cuartetos, Ciudad de mis Sueños) y en el caso de las clases medias /medias altas, la empresa constructora es la que adjetiva la ciudad construida (Ciudad Gama, por ejemplo. Literalmente producida por el grupo empresario Gama).

Peri-centro y peri-ferias, en tanto espacios/tiempos que condensan el despliegue desigual y combinado de las formas de hacer ciudad, mediante las que se expresa la materialización del capitalismo en nuestra ciudad. Así, podemos decir que desde Haussmann y sus bulevares en aquel lejano espacio/tiempo hasta nuestro presente, compulsivamente se manifiesta la reunión de la acción de funcionarios del estado y agentes del mercado, destruyendo los barrios e impidiendo en ellos las manifestaciones plurales de la vida social. Proceso que hoy se transforma es una especie de particular instantánea cuando se observan calles que han devenido en peatonales para la rápida circulación de sujetos que no las habitan; espacios que en algún momento quedan vacíos de personas pero siempre colmados por mercancías 
(Portal Güemes será un particular paquete de experiencia expresivo de esta organización de vivencias turísticas ${ }^{9}$ ). Hay aquí una manifestación de la operatoria de la mercantilización y mediatización de la experiencia, que continuaremos en breve.

En función de lo anterior, creemos haber expuesto con claridad la proposición que construye a la ciudad como instancia de producción activa de relaciones articuladas desde la lógica de la mercancía; es decir a la ciudad como producción de formas de estar juntos y estar separados en escenarios en los cuales cada vez queda más claro el carácter de clase de las uniones y separaciones.

\section{Las tendencias de mercantilización y mediatización de la experiencia. Un acercamiento fenomenológico}

Después de haber argumentado nuestra perspectiva sobre la noción de Ciudad, pasemos ahora a trabajar el par Comunicación/Cultura y la operatoria de las tendencias de mercantilización y mediatización.

Retomemos nuestra hipótesis de trabajo: La trama Comunicación/Cultura; es decir las relaciones sociales por definición plurales y heterogéneas en cuanto a la construcción de significados sobre la vida con otros y con el entorno, sobre la propia experiencia, expresada en los más variados lenguajes, objetivada en distintos soportes, configurada en múltiples géneros, viene siendo subsumida por una forma dominante -la comunicación devenida en discurso publicitario- y expone la marca del mercado en la estructura y en la estructuración de las relaciones sociales. No se trata de un problema de discurso -el discurso publicitario- sino de la identificación de una (la) forma dominante del lazo social: del sujeto consigo mismo, con los otros, con el entorno.

Seth Siegelaub en el primer volumen de "Comunicación y lucha de clases" afirma lo siguiente:

9 https://www.cordoba.gob.ar/centralidades/guemes/

http://www.lavoz.com.ar/ciudadanos/tras-anos-de-anuncios-se-pone-en-obras-el-portal-de-guemes 


\begin{abstract}
Así como Marx dice que en "la producción social de su vida los hombres establecen determinadas relaciones necesarias e independientes de su voluntad, relaciones de producción que corresponden a una fase determinada del desarrollo de sus fuerzas productivas materiales", también podemos decir que los hombres y mujeres establecen relaciones comunicativas que son independientes de su voluntad personal. Como se comunican las personas, donde y cuando se comunican, con quien se comunican e incluso, en cierta medida, que comunican y porque lo hacen -en pocas palabras, la forma o modo de comunicación-, todo ello responde al proceso histórico. Solo considerando estos cuatro elementos (el movimiento de personas, de bienes, de información y, por último, pero no por eso menos importante, de capital) como componentes simultáneos de un proceso global de comunicación, podemos llegar a reconstruir y comprender la comunicación de la forma en que realmente la viven, en un momento dado, las personas: hombres y mujeres, grupos y, en especial, clases. (Siegelaub, en Mattelart, y Siegelaub, 2017: 35)
\end{abstract}

La cita anterior nos permite retornar a dos cuestiones: a- La trama Comunicación/Cultura es expresiva de relaciones heredadas, que nos conforman, en las que entramos a jugar; es decir, la comunicación no es un medio -como erróneamente sostiene la concepción burguesa de la comunicación sensu Benjamin (1999b)- sino que estamos y entramos en el lenguaje y en otros universos de sentido comunicacionales/culturales que son pre-existentes y precedentes; y, b- el proceso global de comunicación en el espacio/tiempo contemporáneo, requiere observar el movimiento de personas, de bienes, de información, de capital en sus emplazamientos, desplazamientos y reemplazamientos característicos, dando cuenta también de las velocidades y direcciones de estos componentes, en el proceso global de comunicación actual. Si la forma o modo de comunicación responde al proceso histórico, nuestra hipótesis de trabajo se funda en el reconocimiento de una forma dominante -la comunicación devenida en discurso publicitario- y expone la marca del mercado en la estructura y en la estructuración de las relaciones sociales: del sujeto consigo mismo, con los otros, con el entorno. Por esto vamos a seguir dando cuenta de la creciente mediatización y mercantilización de la experiencia.

Pero, ¿qué queremos decir con mediatización de la experiencia? Fenomenológicamente, empecemos a reflexionar con lo que tenemos entre manos: el celular como dispositivo 
tecnológico. Si el agua ha devenido mercancía $^{10}$ y pagamos por ella y sus envases individuales y pequeños -producto que interpela a un sujeto solo, que bebe al paso, ya que camina, corre o está sentado frente a una pantalla- en este espacio/tiempo del capitalismo vuelto "primera naturaleza", tenemos aplicaciones gratuitas para entrar/salir/andar por nuestra ciudad y por otras que no conocemos al alcance de la mano. Aplicaciones de mapas, de recorridos y frecuencias de colectivos para las actividades más cotidianas y rutinarias; aplicaciones como street view para acceder a paquetes de experiencia por inmersión en geografías que quizás nunca visitemos. Decíamos antes en referencia a Siegelaub que como se comunican las personas, donde y cuando se comunican, con quien se comunican e incluso, en cierta medida, que comunican y porque lo hacen (las cursivas nos pertenecen) responde a un proceso histórico que modela nuestras relaciones.

Y para retomar entonces la noción de mediatización de la experiencia, interrogándola desde la Comunicación/Cultura, se hace necesario recordar algunos estudios clásicos sobre las transformaciones en la comunicación -es decir, las formas de estar juntos/estar separados-. Desde América Latina, las investigaciones de Jesús Martin-Barbero ya señalaban las significativas diferencias entre las comunicaciones entre los clientes y el vendedor en los almacenes de barrio y la experiencia de estar rodeados de informaciones y publicidades en los grandes almacenes o los shoppings, en los que no necesitamos interactuar con nadie pero si recorrer, desplazarnos obligadamente por el circuito de exposición de las

10 Presintiendo el mal, objetaba Marx al respecto que el hombre que no tenga otra propiedad que su fuerza de trabajo "ha de ser esclavo de otros hombres que se han hecho propietarios". Pese a lo cual, la confusión se extiende y, poco después, Josef Dietzgen declara: "el Salvador de la época actual se llama trabajo... En la mejora del trabajo consiste la riqueza que ahora puede lograr lo que ningún redentor logró antes”. Este concepto marxista vulgarizado de lo que es el trabajo no se detiene mucho ante la cuestión de cómo afecta su producto a los propios trabajadores en tanto no puedan disponer de él; toma en consideración solamente los progresos en el dominio de la naturaleza, no los retrocesos de la sociedad; apunta ya los rasgos de la tecnocracia que luego se encontrarán en el fascismo. Entre ellos está un concepto de naturaleza que se diferencia malhadadamente de la de las utopías socialistas del Vormärz. El trabajo, según se entendió a partir de entonces, se orienta a la explotación de la naturaleza; lo que, con ingenua satisfacción, se contrapone a la explotación del proletariado. Comparadas con esta concepción positivista, las fantasías que dieron tanta ocasión para ridiculizar a Fourier revelan una sorprendente sensatez. Según Fourier, el trabajo socialmente bien constituido traería como consecuencia que cuatro lunas iluminaran de noche la tierra, que el hielo se retrajera de los polos, que el agua marina ya no supiera salada y las fieras salvajes se pusieran al servicio del hombre. Todo ello esclarece un trabajo que, lejos de explotar la naturaleza, puede ayudarla a engendrar las criaturas que como posibles dormitan en su seno. Al corrompido concepto de trabajo pertenece, como complemento suyo, esa naturaleza que, como ha expresado Dietzgen, “está ahí, gratis”. Walter Benjamin, Sobre el concepto de historia, Tesis XI. (2009). 
mercancías-. En nuestro presente, estos cambios se han profundizado. Cada vez necesitamos menos de interactuar con otro, tenemos literalmente la solución de nuestras dudas al alcance de nuestra mano y el milagro de su ocurrencia -que no nos interesa- en la conexión al satélite. Es más, podemos comprar sin salir de casa y "entrar a las tiendas” vía internet. Así como los dispositivos tecnológicos de comunicación cada vez más se pegan a nuestro cuerpo (sus rasgos definitorios son la personalización y la portabilidad, ya señalados por Alberto Bacman y Roberto Quevedo (2004), hoy los productos vienen a nosotros mediante las redes sociales. El lazo publicitario no para, circularmente, de mostrarnos ofertas. O más precisamente: de disponernos delante de las mercancías ${ }^{11}$. No es ninguna novedad que en las formaciones sociales capitalistas lo que se produce no es mercancías para sujetos sino sujetos para mercancías; donde el desarrollo de los medios de transporte -desde los viejos trenes hasta internet- se orienta a aumentar la velocidad del proceso global de producción. Por esto decíamos antes que en nuestra interpretación, Robert Park primero y Ludovico Silva más delante de manera pertinente enfatizaron el lugar de la circulación ${ }^{12}$ en la producción de la vida social. Pero el incremento de la velocidad de la circulación hasta su

11 El primer capítulo de la tercera temporada de la serie Black Mirror, titulado "Caída en picada" nos permite trabajar varios aspectos de los expuestos hasta aquí. El argumento se basa en un futuro ¿́próximo? en el cual los sujetos tienen implantes oculares que utilizan cotidianamente para la calificación de las interacciones sociales, mediante una aplicación que tienen en sus celulares de una escala de puntuación que va de una a cinco estrellas. Las variaciones en la puntuación tienen impacto concreto en las posibilidades de movilidad social. En este capítulo, es significativo que la protagonista ponga en juego la cantidad de puntos obtenida nada menos que para: acceder a una vivienda, un vehículo, a la gasolina para desplazarse.

Nosotros aún no tenemos los implantes oculares, pero día a día, como expresión de una sociedad competitiva y darwinista, en su fase espectacular mercantil, tanto en las instancias de consumo como en las instancias de trabajo, nos vemos interpelados a puntuar y nos sabemos evaluados de manera continua. Somos interpelados como mercaderes y mercancías a la vez, en la expresión de W. Benjamin sobre la figura de la prostituta. Lo que estamos empezando a cuestionar y desarrollaremos en breve es la separación entre "el mundo de las redes" y la vida social. La serie nos proyecta a un tiempo posterior, sin embargo, consideramos que lo más interesante refiere a las tendencias que hoy existen en la experiencia contemporánea.

12 "El momento actual es ya el de la autodestrucción del medio urbano. La explosión de las ciudades sobre los campos cubiertos por "masas informes de residuos urbanos" (Lewis Mumford) es presidida de forma inmediata por los imperativos del consumo. La dictadura del automóvil, producto-piloto de la primera fase de la abundancia mercantil, se ha inscrito en el terreno con la dominación de la autopista, que disloca los antiguos centros e impone una dispersión cada vez más pujante. Al mismo tiempo los momentos de reorganización inconclusa del tejido urbano se polarizan pasajeramente alrededor de "las fábricas de distribución" que son los gigantescos hipermercados edificados sobre un terreno desnudo, con un parking por pedestal; y estos templos del consumo precipitado están ellos mismos en fuga en el movimiento centrífugo que los rechaza a medida que se convierten a su vez en centros secundarios sobrecargados, porque han acarreado una recomposición parcial de la aglomeración. Pero "la organización técnica del consumo no es más que el primer plano de la disolución general que ha llevado a la ciudad a autoconsumirse de esta manera”. Debord, 1995, tesis 174. (Las cursivas nos pertenecen). 
forma contemporánea en la cultura de la conectividad (Van Dijck, 2016) materializada como posibilidad al alcance de la mano y al instante de conexión permanente -conexión que sigue la cuenta del uno a uno, la suma de individuo a individuo- indica la emergencia profundas modificaciones en las formas de socialidad, que van triturando los vínculos con la generación inmediatamente anterior. Con esto sostenemos que la cultura de la conexión permanente no remite a fenómenos que ocurren exclusivamente en la red de redes, sino que la conexión es un rasgo de la Comunicación/Cultura contemporánea ${ }^{13}$ donde la Ciudad misma se trama en este nuevo giro en la forma de participación en la vida social que se afirma como suma de individuos -subordinado a relaciones entre cosas-. Para ser precisa: hoy se habla de Ciudades Inteligentes (veníamos desplazando este adjetivo al mundo de las mercancías, es sintomático que ahora lo asociemos a las ciudades) y de Internet de las cosas. Internet de las cosas es el emplazamiento en la ciudad de diversas y numerosas tecnologías de información que portan censores (cámaras, drones, por ejemplo) para tener información/datos en tiempo real para la toma de decisiones. No vemos muchas zonas de la ciudad que habitamos, no las hemos transitado y quizás no lo haremos, pero delegamos en las tecnologías -cámaras y drones, por ejemplo- el registro y la memoria de lo que allí ocurre. Este despliegue de la "ciudad inteligente" se sostiene en la valoración positiva por parte de sus habitantes, en la suma de redes y paredes - parafraseando a Paula Sibilia (2012)- que dan cuenta de los tradicionales ejercicios de soberanía y control horizontal (paredes como hacer muros, separar las vías de circulación) las nuevas formas de soberanía vertical asociadas a las redes. Por esto al inicio de nuestras reflexiones decíamos: en las ciudades actuales, los pares "carne y piedra” (Sennett) y "técnica y sensorium” (Benjamin) constituyen ejes analíticos para indagar sobre las materializaciones en la ciudad del predominio de relaciones entre cosas que moldean la experiencia urbana de sus habitantes.

Lo señalado hasta aquí la sustantiva modificación de las relaciones sociales, por definición plurales y heterogéneas en cuanto a la construcción de significados sobre la vida con otros

13 "LA VIDA EN VIVO", es el slogan del Canal AMERICA. Las viejas tecnologías de difusión masiva, los viejos medios de difusión de masas /radio, TV/ también se inscriben en las prácticas de conexión en tiempo real: desde la utilización de las redes para recibir mensajes vía celular o web de las audiencias hasta la utilización de cámaras primero y luego drones para mostrar lo que ocurre en algún punto de la ciudad. La llamada información de servicios (que refiere a la circulación) información sobre vuelos, trenes, subtes, cortes de calles y marchas es un referente al momento de analizar como los viejos medios se construyen como "necesarios" para la vida urbana actual. 
y con el entorno, sobre la propia experiencia, expresada en los más variados lenguajes, objetivada en distintos soportes, configurada en múltiples géneros, al ser codificadas como datos, como gran masa de informaciones con un valor comercial para usos políticos/ publicitarios -un mismo género-. La comunicación devenida en discurso publicitario, exponiendo la marca del mercado en la estructura y en la estructuración de las relaciones sociales.

En este ejercicio fenomenológico que venimos describiendo queda claro en la nueva ciudad inteligente que la circulación adquiere una significación especial y específicamente la velocidad diferencial de sujetos, mercancías e ideas. Nuestra experiencia de ciudad es centralmente transitar: vamos de un punto A hacia un punto B. El propio habitante tiene una experiencia no sólo fragmentaria y parcial, sino de flecha. Desde un punto A hacia un punto B y a la vez circular, siempre desde un punto A hacia un punto B. Círculos de encierro en entornos de clase, tal como hemos desarrollado en otros textos. Y así como antes referíamos a los dispositivos pegados al cuerpo y a la velocidad de la circulación en las redes como algo deseable (véanse las publicidades para navegar más rápido, la última publicidad de Movistar que directamente dice/ordena: "paquetizate, compra un pack con más gigas"; "paquete de experiencia” para los círculos de encierro en las redes), la emergencia de rollers y monopatines de los habitantes de la ciudad también configuran un índice tanto de los desplazamientos individuales y del hacer el propio circuito, como del ejercicio de llegar a destino sin necesidad de otros. Otro pliegue de la sociedad de los individuos, que se concreta como suma de dispositivos que acorralan (aunque aparezcan como deseados) al cuerpo de los sujetos. Lo antes dicho transforma el lugar de la calle, reflexionado por Benjamin en sus escritos sobre lo que denominaba “embellecimiento estratégico”. En este sentido, Boito, Espoz y Torres (2018) planteaban:

\footnotetext{
Si en la tesis benjaminana la calle era el lugar "natural” de sociabilización y de expresión de conflictos, ¿qué calles son las de los entornos protegidos, cada vez más planificadas, reguladas controladas, sea ya por el Estado, el Mercado, o por todas las mediaciones tecnológicas que nos "advierten" sobre lo “seguro/inseguro”? ¿Qué otro, son "Otros” que debemos evitar y cuáles los "mismos” para interactuar? Si venimos de una experiencia de configuración de lazo social donde el barrio, como forma organizativa implica a la vez que límites, pasajes que habilitaban múltiples encuentros, ¿qué encuentros son posibles en el marco de entornos cada vez más cerrados -material y tecnológicamente-? (2018: 13)
}

Entonces si calle deviene vía, ¿cómo queda configurada una (nueva) ciudad con innumerables fragmentaciones y separaciones que tienden a evitar el contacto con el otro y 
con lo otro por el miedo? Esta geometría de los desplazamientos y emplazamientos, enfatiza una gramática de las acciones, como conjunto de reglas orientadas a evitar el contacto, a partir de un primer encuadre de organización de la interacción fundado en el miedo, que hace posible la proyección de los fantasmas de clase.

Pero tal como ya hemos indicado, esta forma de mediatización tecnológica se sobre-inscribe en maneras preexistentes de constitución de experiencias fragmentadas. Las decisiones urbanas que hemos caracterizado en nuestra ciudad -así como en otras- trazan islotes en un espacio urbano socio-segregado que a la vez intensifica la socio-segregación. Por esto indicábamos que la mediatización de la experiencia no tiene que ver de manera excluyente con la tecnología, sino con transformaciones urbanas que redefinen las formas de estar/juntos y separados.

Las edificaciones en altura han cambiado las relaciones de vecindad al hacer desaparecer la contigüidad espacial por la superposición vertical; en la ciudad de Córdoba, durante los últimos 25 años se han desarrollado los barrios cerrados y barrios ciudad; pero antes de esto y con la directriz de la densificación de la ciudad, se fueron construyendo edificios de departamentos y modificando las prohibiciones con relación a las zonas y alturas aceptables $^{14}$. En otra geografía distinta a la cordobesa, donde los pobres viven en morros (en algunas ciudades de Colombia, Brasil, entre otros países de la región) el establecimiento de los teleféricos es una muestra que vuelve a reunir la importancia de la circulación, el deseo

14 El urbanismo es la realización moderna de la tarea ininterrumpida que salvaguarda el poder de clase: el mantenimiento de la atomización de los trabajadores que las condiciones urbanas de producción habían reagrupado peligrosamente. La lucha constante que ha debido sostenerse contra todos los aspectos de esta posibilidad de reunirse encuentra en el urbanismo su campo privilegiado. El esfuerzo de todos los poderes establecidos después de las experiencias de la Revolución francesa para acrecentar los medios de mantener el orden en la calle culminará finalmente en la supresión de la calle. "Con los medios de comunicación de masas que eliminan las grandes distancias, el aislamiento de la población ha demostrado ser un modo de control mucho más eficaz", constata Lewis Mumford en "La ciudad a través de la historia". Pero el movimiento general del aislamiento que es la realidad el urbanismo debe también contener una reintegración controlada de los trabajadores según las necesidades planificables de la producción y el consumo. La integración en el sistema debe recuperar a los individuos en tanto que individuos aislados en conjunto: tanto las fábricas como las casas de cultura, los pueblos de veraneo como "las grandes urbanizaciones" están especialmente organizados para los fines de esta seudo-colectividad que acompaña también al individuo aislado en la célula familiar: el empleo generalizado de receptores del mensaje espectacular hace que su aislamiento se encuentre poblado de imágenes dominantes, imágenes que solamente por este aislamiento adquieren su pleno poder (Debord, 1995, tesis 172). 
de velocidad y a la vez muestra el carácter penal del arte de la edificación. La práctica de subir y bajar para los habitantes de los barrios populares que viven en los morros y el deseo de "llegar volando" a la ciudad se tradujo en cambios urbanos como por ejemplo en Medellín con la instalación de los teleféricos. Pero aquí es evidente que la vía está abierta para las distintas clases e intencionalidades, ya que garantiza la movilidad de los habitantes, así como la entrada más rápida de la policía y los nominados pornográficamente "operativos de pacificación". 15

La circulación y la velocidad se sostienen y a la vez orientan el carácter penal de las intervenciones urbanas contemporáneas, que se constituyen en un lazo solidario entre urbanismo y seguridad; así los procesos de segregación residencial están marcados con contenidos de clasificación de la población y de zonas como seguras e inseguras. Proceso a partir del cual los viejos medios ven potenciada su capacidad y su función ideológica: muros reales como condición de posibilidad para muros mentales que hacen posible la proyección de estructuras de experiencia sostenidas por el miedo a los otros y la legitimación de los dispositivos para circular y no encontrarse ${ }^{16}$. Retomando lo afirmado por Boito, Espoz y Torres (2018):

(...) Recuperamos una "vieja” pregunta del campo de la comunicación (¿cómo se comunican las personas en la ciudad y de qué nos habla esa cotidianidad?) para dar cuenta de las injerencias de estas formas de segregación, separación y privatización del espacio en las

15 Sobre este tema hemos trabajado con la Lic. Alejandra Peano, Ver: Boito, M. E. y Peano, A. (2018): Urbanismo en Clave Securitario. Descripción y Análisis del Plan de Seguridad Provincial (Córdoba, 2015-2017). Congreso Internacional Vivienda y Ciudad: Debate en torno a la nueva agenda urbana, Córdoba, Argentina, junio 2018.

$16 \mathrm{La}$ angustia que nos produce el miedo es -paradójicamente- la que nos impone el orden de la ciudad. Y ese orden se construye a partir de la incertidumbre que nos genera el otro, un orden que cimenta la desconfianza hacia lo desconocido tornándolo sospechoso. Y ante lo indescifrable de los sujetos-objetos de la ciudad, estos mega-emprendimientos proponen entornos seguros, protegidos, conocidos. Por un lado, podemos referirnos a una vuelta a lo disciplinar a partir de la administración del control en los espacios: claves y garitas de seguridad para entrar y salir del complejo, guardias en los ingresos de los edificios y countries, rondines vehiculares y alarmas, horarios definidos para circular-desplazarse en ese adentro que configura la micro-ciudad (para ir al gimnasio, para usar los espacios compartidos, para usar el servicio de lavandería de ropa, etc.). Luces y cámaras de seguridad que posibilitan la vigilancia continua, la vigilancia modulada por dosis de control cotidiano auto-administrado. Accionar un botón, dar aviso a los guardias del complejo, circular por espacios limpios e iluminados se construyen como modos de estar juntos con todos aquellos que eligen una experiencia similar. (Boito, Espoz y Torres, 2018: 16-17) 
formas de "estar juntos" o, dicho de otra manera, en las formas de estructuración sociales (por ende, en las formas de relacionarnos socialmente) (2018:12).

La experiencia descripta hasta aquí aparece como un lugar clave para comprender las disposiciones, posiciones y posibilidades e imposibilidades interaccionales de nuestro presente, en el marco de una ciudad clasista en la que de lo que se trata es de castigar a los pobres -sensu Loïc Wacquant (2010)- vigilando que no se muevan de los espacios fijados para habitar-circular-trabajar en una geometría clasista de la ciudad, que determina el par cuerpo/clase desde hace décadas. En esta dirección desde África, las elaboraciones sobre la noción de Necropolítica y gobierno privado indirecto de Achille Mbembe (2011); y desde América Latina, la noción de Capitalismo Gore de Sayak Valencia (2010) dan cuenta de la violencia estructural junto a la producción sobre la dronización de la vigilancia, la soberanía vertical y los desplazamientos desde la idea de guerra hacia la de cacería descriptas por Gregoire Chamayou $(2016,2012)$ en este espacio/tiempo de la cacería del hombre.

\section{Conclusiones}

Hasta aquí hemos dado cuenta de la trama que reúne Ciudad/Comunicación/Cultura, al momento de interrogar las maneras de producción de estar juntos/estar separados en los escenarios urbanos actuales. En el cierre de estas reflexiones partimos de una especie de imagen que -desde nuestra perspectiva- condensa no sólo un determinado estado de las relaciones sociales (más precisamente entre clases sociales)- sino que además evidencia la potencia epistémica y política de esta mirada transdisciplinaria, en vistas a identificar el carácter tanático en la producción de ciudad actual.

Mientras escribía este texto y al mismo tiempo que muchos televidentes del país esperaban el regreso del programa Showmatch por TV (03/09/2018)-programa con formato global, que expresa la operatoria de la economía espectacular mercantil en la forma de los medios de difusión audiovisual y también ejemplifica la significación del momento de la circulación en los procesos de producción social de los sentidos- un niño fue asesinado en Roque Sáenz Peña, en la provincia de Chaco en el marco de un intento de saqueo. Fue asesinado por balas disparadas por parte de quienes, atravesados por vivencias crecientes de miedo y desprotección, salen literalmente disparados a defender la mercancía por sobre la vida.

Las notas de los medios que aparecían en Internet se armaban con imágenes relevadas por quienes estuvieron allí vía lo registrado con sus celulares, se copiaron los Tweet emitidos 
desde la intendencia y la gobernación de Chaco e incluso en algunas notas hay imágenes de un muro de Facebook donde se propone salir a saquear. $\mathrm{Y}$ en cada medio digital de los consultados, en el marco de formas de comunicación/cultura que se sostienen y legitiman en la conectividad permanente y la participación mediada instantánea, hubo espacio para los comentarios de los cibernautas y los recurrentes insultos por la discrepancia de opiniones. Velozmente el hecho fue "cubierto"; fundamentalmente por la heterogeneidad y variedad de la forma "comentario" en el orden del discurso -sensu Foucaultaudiovisual/actual (notas al instante, tweet y posteos de Facebook, para ingresar al otro día en la rutina de los viejos medios audiovisuales y gráficos, ocupando diversa jerarquía en función de la distancia con el hecho) pero fue cubierto también por el proceso activo de atracción/direccionamiento de la visión que aún mantienen los viejos medios, fundamentalmente la TV en el horario de la noche.

Esta doble imagen (las miradas de los televidentes centradas en la vuelta de Tinelli y la nueva edición de "Bailando por un sueño" en el régimen de los viejos medios y el registro de la producción de imágenes y palabras al instante del asesinato en la ciudad chaqueña y la subida a las redes sociales) dan cuenta no sólo de nuevas modalidades de aislamiento por comunicación a las ya teorizadas por Horkheimer y Adorno (recordemos además la propuesta de Ludovico Silva de cambiar la noción de industria cultural por industria ideológica en la década de los años 70) sino de su creciente incidencia en el espacio/tiempo de la comunicación/cultura de la conectividad, de la digitalización como flujo en el que actuamos por inmersión. Aquí la cultura de la conectividad en su materialización en las redes sociales y en el espacio virtual muestra sus rasgos de círculos de encierro, y concreta la crítica en acto del carácter ideológico de la posibilidad/deseo de conexión permanente. La noticia va a tener en ese momento, y también más adelante, recorridos/reconocimientos delimitados. Por otra parte, la doble imagen referida enfáticamente indica su lazo con la mercancía. El terror dulce asociado al espectáculo y la competencia estetizada que atrapa al ojo -esa "golosina caníbal", en la expresión de Stevenson retomada por Bataille- coexiste en el mismo instante con el terror crudo del reino de las mercancías que se dispone más allá de las necesidades de los sujetos y que se cobra con vidas cuando no es reconocido como tal. La doble imagen también señala la pertinencia de la afirmación benjaminana sobre la dispersión de la atención como rasgo de las experiencias en ciudades que estaban atravesando convulsionados procesos de cambio. En el marco del peso creciente de la red de redes, los antiguos medios encuentran dificultades tanto para atraer y mantener la atención (en comparación con vivencias asociadas no ya a la pasividad sino por el contrario a un 
frenético hacer en simultáneas ventanas, típico de este momento de las ciberculturas) como para lograr simular la integración en un imaginario urbano cada vez más disgregado y fragmentado. Por el contrario, si encuentran fuerza para potenciar la pasión del miedo en las ciudades, que opera también aislando. Dice Martín-Barbero:

\begin{abstract}
¿De qué está hecho el orden urbano, a través de qué funciona? Paradójicamente se trata de un orden construido en base al crecimiento de la incertidumbre que nos produce el otro, un orden que inocula en nosotros la desconfianza hacia todo el que-me-mira-mal en la calle. Pues en la calle se ha vuelto sospechoso todo aquel que haga un gesto que no podamos descifrar en veinte segundos. Y entonces ese otro, convertido cotidianamente en amenaza, ¿no tiene mucho que ver con lo que está pasando en nuestra cultura política, con el crecimiento de la intolerancia, con la imposibilidad de ese pacto social del que tanto se habla, con la dificultad de reconocerme en la diferencia de lo que el otro piensa, con lo que al otro le gusta, o lo que el otro tiene como horizonte vital, estético o político? (Martín-Barbero, 2015: 11-12)
\end{abstract}

Continua el autor:

Pues los miedos (...) son expresión de una angustia honda, de una angustia cultural. Angustia que proviene de varios factores. En primer lugar, de la pérdida del arraigo colectivo en unas ciudades en las que un urbanismo salvaje - pero que, a la vez, obedece a un cálculo de racionalidad formal y comercialva destruyendo poco a poco todo paisaje de familiaridad en el que pueda apoyarse la memoria colectiva. Y en segundo lugar, es una angustia producida por la manera como la ciudad normaliza las diferencias. Se echa la culpa a los medios de comunicación de homogeneizar la vida cuando el más fuerte y sutil homogeneizador es la ciudad, impidiendo la expresión y el crecimiento de las diferencias. (MartínBarbero, 2015:19)

Lo que tratamos de enfatizar es que -como bien afirmaban los situacionistas y hoy encontramos modos más veloces y dispares- el urbanismo y tecnología actúan como el alfa y el omega de la separación, aunque paradójicamente se sostengan en modos reactivos de "relacionarse y las maneras que tiene la gente de estar/sentirse juntos" (Martín-Barbero, 2015: 13) entre los que se reconocen como partes de una mini/micro ciudad. Quizás lo más escandaloso de este presente no sea el carácter público/mediado/mercantilizado de la vida privada sino la disolución de lo público como espacio con otro, más allá de las maneras reactivas/defensivas que hemos descripto.

En la presentación del Volumen I de la edición de "Comunicación y lucha de clases" (2017), Sierra Caballero afirma con relación a los desafíos de la investigación en el presente: 
La lucha epistemológica de reconfiguración del campo crítico de la comunicación pasa, a nuestro entender, por limitar y definir el alcance del giro lingüístico de los estudios culturales, reconectando pensamiento y capitalismo, discurso y realidad, y la centralidad de la lucha por el código en la nueva forma de reproducción del capital (Sierra Caballero en Mattelart y Siegelaub, 2017:15)

Desde nuestro lugar de lectura, la lucha epistemológica pero primariamente política necesita de un primer momento exposición del presente, para identificar los crueles procesos de aislamiento por decisiones urbanas sobre el habitar/circular y por la operatoria de tecnologías pegadas al cuerpo que conforman un nuevo pliegue a la sociedad de los individuos. Siguiendo la cuenta del uno, del uno a uno, los sujetos vamos participando de comunidades que actúan como círculos de encierro. Fenomenológicamente de nuevo, sujetos con dispositivos pegados al cuerpo, en barrios cerrados, con trayectorias fijas de movilidad por la ciudad manifiestan la pregnancia de las tendencias de mercantilización y mediatización de la experiencia que nos constituyen, conformando nuestra sensibilidad y el sensorium colectivo. Este intento de montar una instantánea que haga posible cierta analítica del presente se dirige a interpelar la ingobernabilidad o a la incorregibilidad, lo que quede de ella o lo que emerge, ante la cruenta transformación de las ciudades que habitamos. 


\section{Referencias bibliográficas}

AA. VV. (1999): De la miseria en el medio estudiantil y otros documentos. Traducción del francés de Diego Luis Sanromán Logroño. España: Pepitas de Calabaza.

BACMAN, R. y QUEVEDO, A. (2004): Los consumos culturales en la Argentina. Informe 2004 del Sistema Nacional de Consumos Culturales de la Secretaría de Medios de Comunicación de la Presidencia de la Nación Argentina. Disponible en: https://es.scribd.com/document/74925718/publicacion-revista-observatorio-4

BADENES, D. (2007): Comunicación y ciudad: líneas de investigación y encuentros con la historia cultural urbana. Revista Question, Revista especializada en Periodismo y Comunicación, 14 (1), pp. 1-11.

Disponible en: http://perio.unlp.edu.ar/ojs/index.php/question/article/view/354.

BENJAMIN, W. (1999a): Poesía y Capitalismo. Iluminaciones II, España. Madrid: Editorial Taurus.

(1999b): Para una crítica de la violencia y otros ensayos. Iluminaciones IV, España. Madrid: Editorial Taurus.

(2009): Tesis sobre la historia y otros fragmentos. Traducción y presentación de Bolívar Echeverría. Rosario: Prohistoria Ediciones, p. 68.

BOITO, M. E. (2013): Ideología y prácticas sociales en conflicto. Una introducción. Con Comité Editorial. Dirección de Publicaciones de la UNC, CIECS-CONICET/UNC.

(2014): Capitalismo, sensibilidad, violencia: forma mercancía y sensibilidad snuff. Revista Fundamentos en Humanidades, 15 (24), Universidad Nacional de San Luis.

BOITO, M. E. y ESPOZ, M. B. (Comp.) (2014): Urbanismo Estratégico y Separación clasista. Instantáneas de la ciudad en conflicto. Rosario: Puño y Letra, Editorialismo de base.

BOITO, M. E., ESPOZ, M.B. y TORRES, P. (2018): Nuevas Dinámicas Socio-Urbanas en Contextos de Turistificación y Patrimonialización: La Cultura Barrial en Conflicto (Córdoba, Argentina). 56 Congreso de Americanistas, Salamanca, España, 15 al 20 de julio de 2018. 
BOITO, M. E. y PEANO, A. (2018): Urbanismo en Clave Securitario. Descripción y Análisis del Plan de Seguridad Provincial (Córdoba, 2015-2017). Congreso Internacional Vivienda y Ciudad: Debate en torno a la nueva agenda urbana, Córdoba, Argentina, junio 2018.

CHAMAYOU, G. (2012): Las cazas del hombre. El ser humano como presa de la Grecia de Aristóteles a la Italia de Berlusconi. Traducción de María Lomeña Galiano. España. Editorial: Errata Naturae. (2016): Teoría del Dron. Buenos Aires. Editorial: Futuro Anterior.

DEBORD, G. (1995): La sociedad del espectáculo. Buenos Aires. Editorial: La Marca. (2000): In girum imus nocte et consumimur igni. Edicion crítica aumentada con notas diversas del autor, seguido de Basuras y escombros. Traducción de Luis Andrés Bredlow, Barcelona: Anagrama.

(2006): El planeta enfermo. Barcelona: Anagrama. Colección Argumentos. Disponible en: https://doi.org/10.18861/ic.2017.12.1 [Consultado: 17-10-2018]

GARCÍA-CANCLINI, N. (1982): Las Culturas Populares en el Capitalismo. México: Editorial Nueva Imagen/ Grijalbo.

HARVEY, D. (2008): El derecho a la ciudad, Revista New Left, no.53. pp. 23-39. Disponible en: http://newleftreview.es/53. [Consultado: 17-10-2018].

JAPPE, A. (1998) Guy Debord. Barcelona. Editorial: Anagrama.

JAPPE, A., KURZ, R. y ORTLIEB, C. (2014): El absurdo mercado de los hombres sin cualidades. Ensayos sobre el fetichismo de la mercancía, Traducción del alemán de Luis Andrés Bredlow, Emma Izaola Logroño, Segunda edición, España: Editorial Pepitas de Calabaza.

KURTZ, R. (2016): El colapso de la modernización. Del derrumbe del socialismo de cuartel a la crisis de la economía mundial. Buenos Aires: Editorial Marat.

MARTÍN-BARBERO, J. (2015): ¿Desde dónde pensamos a comunicación hoy? Revista Chasqui, Revista Latinoamericana de Comunicación, no.128, pp. 13-29. Disponible en: http:// chasqui.ciespal.org/index.php/chasqui/article/view/2545. 
MATTELART, A y SIEGELAUB, S. (Eds.) (2017): Comunicación y lucha de clases. Vol. 1. Capitalismo, Imperialismo, 1era edición en español, Quito: Ediciones CIESPAL, Colección: Economía y Políticas de Comunicación, $\mathrm{N}^{\circ}$ 11. Coordinación y edición general de la versión en español: Mariano Zarowsky.

MBEMBE, A. (2011): Necropolitica. España: Editorial Melusina.

MEZZADRA, S. (2014): La cocina de Marx. El sujeto y su producción. Traducción Diego Picotto, Buenos Aires: Editorial Tinta Limón.

MOLINATTI, F. (2013): Segregación residencial socioeconómica en la ciudad de Córdoba (Argentina): Tendencias y patrones espaciales. Revista INVI, 28 (79), pp. 61-94. Disponible en: http://www.revistainvi.uchile.cl/index.php/INVI/article/view/778 [Consultado: 17-102018]

REGUILLO, R. (1997): Ciudad y comunicación. Densidades, ejes y niveles. Diálogos de FELAFACS, no. 47, pp.33-42.

Disponible en: http://dialogosfelafacs.net/wpcontent/uploads/2015/74/74-revistadialogos-ciudad-y-comunicacion.pdf [Consultado: 17-10-2018]

SCHOLZ, R. (2013): El Patriarcado Productor de mercancías. Tesis sobre Capitalismo y Relaciones de Género en Constelaciones Revista de Teoría Crítica, no. 5. Disponible en: http://constelaciones-rtc.net/article/view/815/869 [Consultado: 17-10-2018]

SAYAK, V. (2010): Capitalismo Gore. España: Editorial Melusina.

SCHMUCLER, H. (1997): "La investigación (1982): un proyecto de comunicación cultura". En Memoria de la comunicación. Buenos Aires: Editorial Biblos.

SENNETT, R. (1997): Carne y piedra. El cuerpo y la ciudad en la civilización occidental. España: Editorial Alianza.

SIBILIA, P. (2012): ¿Redes o paredes? La escuela en tiempos de dispersión. Buenos Aires: Editorial Tinta Fresca. 
SILVA, L. (1977): La Plusvalía Ideológica. Caracas: Ediciones de la Biblioteca de la Universidad Central de Venezuela (3era edición).

VAN DIJCK, J. (2016): La cultura de la conectividad. Una historia crítica de las redes sociales. Buenos Aires: Siglo XXI Editores.

VERA, P. (2017): Ciudad y comunicación: la actualidad de un campo transdisciplinar. Revista InMediaciones de la Comunicación. Ciudad y comunicación, imaginarios, subjetividades y materializaciones. $12 \quad$ (1), pp. 21-35. DOI: https://doi.org/10.18861/ic.2017.12.1

WACQUANT, L. (2010): Castigar a los pobres: el gobierno neoliberal de la inseguridad social. Barcelona: Editorial Gedisa. 